Article

\title{
How Does Car Parking Availability and Public Transport Accessibility Influence Work-Related Travel Behaviors?
}

\author{
Hannah M. Badland *, Nick Garrett and Grant M. Schofield \\ Centre for Physical Activity and Nutrition, Auckland University of Technology, Private Bag 92006, \\ Auckland, New Zealand; E-Mails: nick.garrett@aut.ac.nz (N.G.); gschofie@aut.ac.nz (G.M.S.) \\ * Author to whom correspondence should be addressed; E-Mail: hannah.badland@aut.ac.nz; \\ Tel.: +64-9-921-9999 Ext. 7630; Fax: +64-9-921-9746.
}

Received: 6 January 2010 / Accepted: 11 February 2010 / Published: 12 February 2010

\begin{abstract}
This study investigated the relationships between car parking, public transport, travel behaviors, and health outcomes for adults $(n=1,188)$ traveling to a worksite. Public transport was used for $12.1 \%$ of the work-related commute. Those who had higher levels of walking, no worksite car park access, lived proximal to a public transport stop, had limited automobile availability, traveled to the main business district, perceived public transport as accessible, or did not have company car access were more likely to use public transportation. Accordingly, proximal residential transit stops and restrictions for company car accessibility and parking at the worksite are needed.
\end{abstract}

Keywords: adults; car parking; public transport; physical activity; global positioning systems

\section{Introduction}

Recently, much focus has been on the relationship between the built environment and physical activity accumulation through different modes of travel [1-4], and within the new urbanism movement there is consensus that neighborhood design and infrastructure influences individual travel mode choices [5-7]. Yet, despite identification and adoption of a myriad of travel demand management and land use planning strategies by local government, private automobiles remain the most common mode of travel to and from an occupation [8]. Automobiles also make a substantial contribution to greenhouse-gas emissions, and it is now recognized that many strategies employed to mitigate the 
effects of climate change (e.g., reducing private car use) can have major benefits for public health [9]. Work-related commuting via private automobile is associated with substantial traffic congestion [10], air pollution [11,12], and reduced overall physical activity accumulation [13,14]. For example, recent evidence demonstrated that commuting by public transport contributed to overall physical activity accumulation; US adults accumulated on average 19 minutes per day of walking by commuting to and from public transport infrastructure [15,16]. As such, engaging in modes of transport that incorporate an active component to a destination that is frequently accessed (such as a worksite) may have utility for improving population-level health outcomes.

To date, the majority of this research is limited to understanding these associations at the neighborhood level, yet an individual's place of work is frequently located outside of their 'local neighborhood', and car parking availability at the worksite and public transport accessibility variables are often external to the scope of these studies. Accordingly, this paper focuses on the life spaces where people live and work and examines travel behavior between these settings. The present work is based on a theoretical framework constructed by Handy et al., [17], where travel is considered a derived demand to access destinations and activities (e.g., place of employment). Within this conceptual model various elements of land use patterns, urban form, and transport systems work together to inhibit or facilitate active and public transport modes, and it is likely that commute journey connectivity, travel distance, and end-point transport infrastructure, such as car parking availability and public transport access, play critical roles in travel mode selection for adults traveling to their place of work. To our knowledge the relationships between specific urban design variables (worksite car parking availability, public transport access, worksite location), travel measures (vehicle access), and health outcomes (overall physical activity, body size) with commuting to work by private vehicle or public transport have not been investigated at the disaggregate level. It is likely that having a better understanding of these associations will result in the development of appropriate land use planning strategies and infrastructure provision to increase the use of sustainable transport modes (e.g., public transport, walking and cycling) to places of employment.

Accordingly, this research was undertaken on a sample of New Zealand working adults. New Zealanders report high private automobile reliance [18] and similar travel behaviors to other non-European developed countries [8,19]; therefore these findings will be largely transferable to other westernized countries. Further understanding of these relationships will provide policy makers, urban planners, and public health agencies with more evidence about how urban design, travel, and health variables interact with travel mode selection for employed adults so as sustainable transport interventions and land use policies can be developed. As such, the objectives of this study are to investigate how urban design, travel, and health variables influence work-related travel behaviors.

\section{Methods}

\subsection{Study Sample}

The Active Friendly Environments Survey (AFES) was implemented in a representative adult sample of residents from North Shore City (Auckland, New Zealand) in April 2005 (autumn). Case weights were applied retrospectively to align the sample with census data based on gender and age 
stratification for the region. Detailed recruitment procedures are described elsewhere [20]. Briefly, potential respondents were drawn randomly without replacement from the North Shore City electronic telephone white pages and contacted through computer assisted telephone interview (CATI) procedures. Within each household contacted, the English-speaking adult ( $\geq 16$ years of age) with the next birthday was asked to partake in the survey. Respondents provided informed consent prior to participating in the survey and the host institution ethics committee approved the study protocol (application 05/40).

\subsection{Auckland Region Profile}

Coastal parts of North Shore City were initially settled in the early 1800 's. From that time onwards North Shore City has become increasingly populated and developed. Currently North Shore City encompasses 12,979 hectares of land, 140 kilometers of coastline, and has approximately 212,000 residents. The wider Auckland region includes 500,116 hectares and is made up of seven districts (Figure 1) with a total population of 1.4 million residents [21]. There are several main commercial settings across the region including industrial parks, universities, a primary central business district (Auckland City), and secondary central business areas in each of the districts, as well as smaller business communities existing in many suburbs. The main travel route from North Shore City to Auckland City is restricted to motorized transport, including ferry and bus, due to the route being via a harbor bridge without pedestrian or cycle access.

Figure 1. Greater Auckland Region.
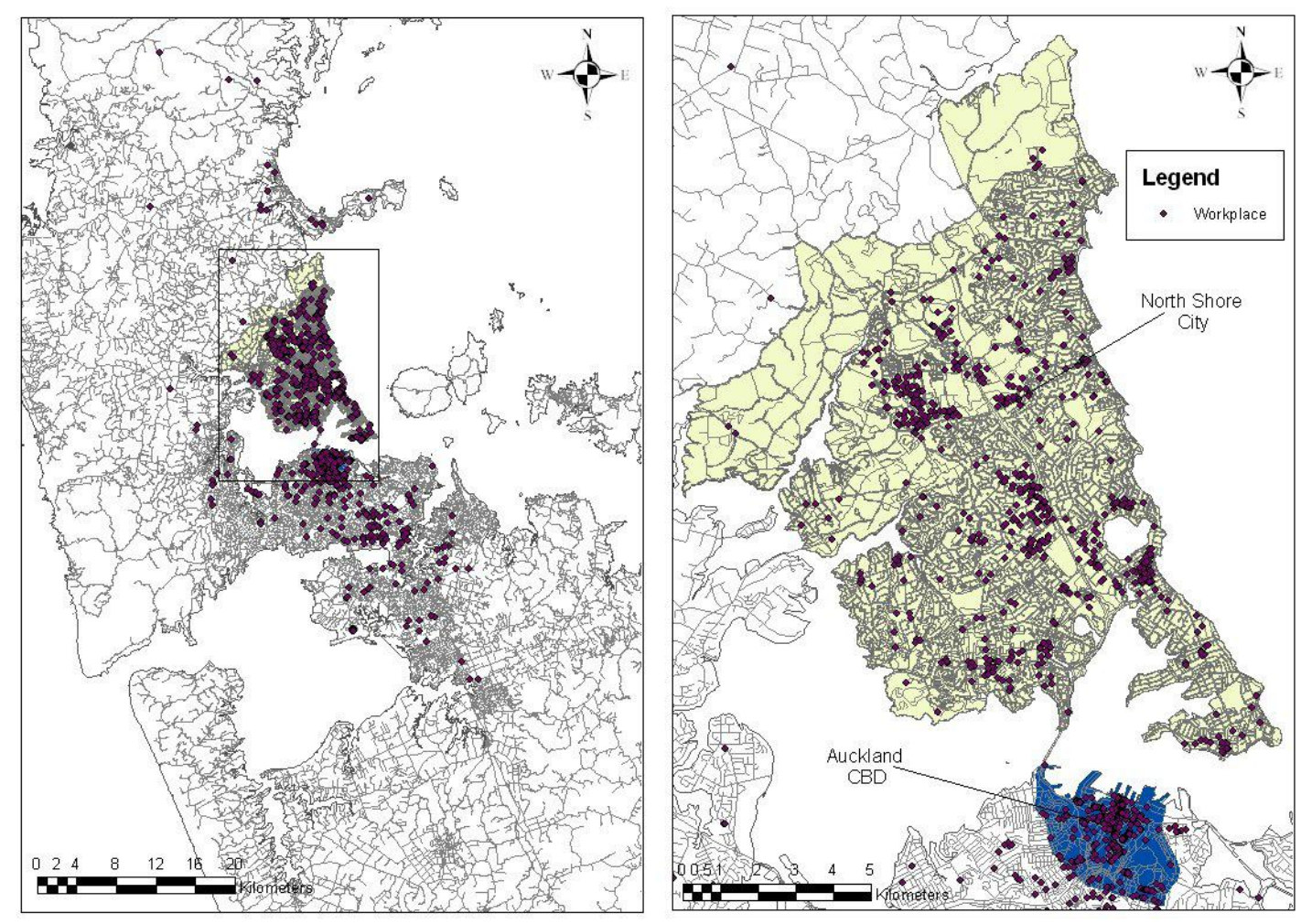


\subsection{Questionnaire Design}

The AFES was an 88-item instrument in part based on a New Zealand adult population-level health survey [22], and also included a travel component [23]. Amongst other things, the AFES assessed variables related to traveling to place of work or study. These included: actual and perceived travel mode selection, work-related travel requirements, car parking availability, private motor vehicle accessibility, and respondents' residential and place of work/study addresses. The work-related travel modality and car-parking availability measures have demonstrated appropriate test-retest reliability [23], and validity and reliability testing has been conducted on the physical activity measures [24]. A copy of the complete questionnaire is available from the authors on request.

\subsection{Urban Design Measures}

\subsubsection{Perceived car parking availability}

Perceived work-related car parking availability was established by asking respondents to respond yes or no to the question: 'If needed, I can always access car parking at or near my worksite'.

\subsubsection{Residential access to public transport}

Respondents' residential addresses and public transport stops were spatially mapped using geographical information systems (GIS) methods (ArcView v.9.0). Street network distance to the closest public transport stop was calculated utilizing the ArcView Network Analyst tool. The distances were then categorized into quartiles.

\subsubsection{Worksite location}

Worksite addresses were self-reported by respondents and were subsequently collapsed into three regions. 'North Shore City' was delimited to the North Shore City region, 'Auckland CBD' consisted of the major central business district (CBD) of the Auckland region and was confined to the area within the inner city circle bus route (within which the majority of car parking is restricted), and the 'wider Auckland' area was the region outside of the aforementioned areas.

\subsubsection{Commute distance}

Street network distance was calculated between respondents' residential and worksite addresses using OD cost-matrix GIS methods. 


\subsection{Travel Measures}

\subsubsection{Travel mode}

The travel mode component of this study was drawn from the survey section that reported typical transport modalities for commuting from residence to place of work or study. Respondents were asked: 'How do you usually get to and from your place of work?' These answers were collapsed into three travel mode categories; motorized, transport-related physical activity (walking, cycling), and public transport (ferry, bus). Only respondents utilizing motorized and public transport modes were used for comparison in this study.

\subsubsection{Access to a private automobile}

Respondents reported on their level of private automobile availability. This was established by asking respondents: 'Regardless if you drive, what level of access do you have to a personal motorized vehicle?' Categories available for respondents to choose from were: unrestricted, frequent, limited, or none.

\subsubsection{Driver's license}

Respondents reported yes or no to whether they held a current New Zealand driver's license.

\subsubsection{Automobile requirements for work}

Work-related automobile requirements were established by asking respondents to respond yes or no to: 'Does the nature of your occupation require the use of a motorized vehicle?' If the respondents answered yes to this question, they were then asked: 'Do you have unlimited access to a company car'? These two questions were then categorized respectively into: no requirements, required for work, and access to company car.

\subsubsection{Public transport accessibility}

Perceptions of public transport accessibility were assessed by respondents defining on a Likert scale how accessible public transport was within their (self-defined) neighborhood.

\subsection{Health Measures}

\subsubsection{Physical activity classification}

Participants recorded frequency and minutes spent engaged in moderate intensity (including walking) and vigorous intensity activities for all purposes over the seven days preceding the survey. Minutes engaged in vigorous intensity activity were equated with moderate intensity activity by being 
multiplied by two [25]. After equating vigorous intensity activity, respondents were classified into dichotomous physical activity groups based on the international best practice recommendation of adults accumulating 30 minutes of moderate intensity physical activity accumulation on at least five days per week [26]. 'Insufficiently active' participants did not report a threshold of five episodes of physical activity, totaling 150 minutes over the previous week. 'Sufficiently active' respondents recorded at least five sessions of physical activity equaling 150 minutes or more over the last week. Time spent walking was also examined; the number of minutes spent engaged in brisk walking per week was categorized into quartiles and included in the models.

\subsubsection{Body mass index}

The body mass index (BMI) classifications were derived from respondents' self-reported height (meters [m]) and body mass (kilograms [kg]) data. The standard BMI calculation was used (weight $(\mathrm{kg}) /$ height $(\mathrm{m})^{2}$ ), with mutually exclusive cut-off points applied to determine BMI classifications for underweight, normal weight, overweight, and obese for those of differing ethnic descents: Asian, <18.5, 18.5-22.9, 23.0-24.9, and >25.0, respectively; Caucasian, <18.5, 18.5-24.9, 25.0-29.9, and >30.0, respectively; and Polynesian, <18.5, 18.5-25.9, 26.0-31.9, >32.0, respectively [27].

\subsection{Statistical Analyses}

Using SAS version 9.1 (www.sas.com), analyses examined the associations between the proposed independent variables (demographics, urban design, and travel measures) and the dependent variable (travel mode by public versus private motorized transport) by utilizing logistic regression analysis and adjusting for design effects of age, sex, and sample weighting. In the present, study spatial distribution of participants was checked to ensure a representative geographic spread across suburbs was achieved, and no further potential confounding effects of spatial clustering were not considered. Socio-demographic (Table 1), urban design and travel measures (Table 2) were examined for association with use of public transportation. Factors found to have significant relationships to travel mode were considered for inclusion in a multivariate logistic regression analysis together with the design effects, and a model was created to predict travel mode by utilizing stepwise variable selection methods.

\section{Results}

Overall, 6,476 eligible respondents were contacted and invited to participate in the AFES before the final sample of 2,000 respondents was recruited (31\% response rate). The response rate was similar to other recently conducted CATI surveys [28,29]. This analysis was further limited to survey participants that were: in paid work, routinely travel to work by either public or private motorized transportation, and had a single work destination. Of the 2,000 respondents surveyed, 14 were outside of the target study area, 124 were students, 466 did not work or worked from home, 94 used active transportation only (walked or cycled) or did not report travel mode, and 114 reported multiple work destinations or did not report a work destination. This resulted in 1,188 respondents being included in 
the present analysis. Within this sample, 18 participants reported no direct access to a private automobile and 26 respondents had limited access to a personal vehicle, therefore it was not feasible to model the non-car access participants separately.

Overall, $12.1 \%(\mathrm{n}=144)$ of the sample reported routinely commuting to and from their place of work utilizing public transport for at least part of their trip. Those who were married or in a de facto relationship ( $\mathrm{OR}=0.53$ ) or divorced / separated / widowed $(\mathrm{OR}=0.50)$ were less likely to use public transport as a work commute mode when compared to respondents who were single (Table 1). Household income, ethnicity, and chronic illness were not related to the likelihood of using public transport to travel to a worksite. Also, no significant associations existed between sufficient physical activity level classification and BMI with engaging in public transport to commute to the worksite. The number of minutes of brisk walking per week was associated; those who walked for 100-210 minutes per week were more likely to use public transportation when compared to the referent category.

Table 1. Socio-demographic profile of respondents and the likelihood of commuting to work by public transport.

\begin{tabular}{|c|c|c|c|c|c|}
\hline & $\mathbf{n}$ & $\begin{array}{l}\text { Use public } \\
\text { transport to } \\
\text { commute to } \\
\text { work (\%) }\end{array}$ & OR* & $95 \% \mathrm{CI}$ & p-value \\
\hline Marital status & & & & & 0.01 \\
\hline Single & 257 & 22 & 1.00 & Referent & \\
\hline Married / de facto & 797 & 10 & 0.53 & $(0.35,0.81)$ & \\
\hline $\begin{array}{l}\text { Divorced / separated / } \\
\text { widowed }\end{array}$ & 132 & 8 & 0.50 & $(0.23,1.09)$ & \\
\hline Annual household income (NZ\$) & & & & & 0.85 \\
\hline$<\$ 40,000$ & 170 & 12 & 1.00 & Referent & \\
\hline$\$ 40,000-\$ 80,000$ & 393 & 11 & 0.83 & $(0.49,1.43)$ & \\
\hline$\$ 80,001-\$ 120,000$ & 304 & 10 & 0.83 & $(0.47,1.46)$ & \\
\hline$>\$ 120,000$ & 206 & 17 & 0.76 & $(0.41,1.42)$ & \\
\hline Not reported & 115 & 14 & - & - & \\
\hline Ethnicity & & & & & 0.65 \\
\hline European / Pakeha & 989 & 11 & 1.00 & Referent & \\
\hline Maori & 47 & 15 & 1.18 & $(0.51,2.72)$ & \\
\hline Pacific Island & 15 & 20 & 1.47 & $(0.44,4.93)$ & \\
\hline Asian & 87 & 20 & 1.53 & $(0.86,2.71)$ & \\
\hline Other & 45 & 11 & 1.03 & $(0.41,2.58)$ & \\
\hline Chronic illness & & & & & 0.69 \\
\hline Yes & 211 & 12 & 1.00 & Referent & \\
\hline No & 977 & 12 & 0.91 & $(0.57,1.45)$ & \\
\hline Body mass index & & & & & 0.84 \\
\hline Underweight / normal weight & 608 & 13 & 1.00 & Referent & \\
\hline Overweight & 386 & 11 & 1.01 & $(0.67,1.51)$ & \\
\hline Obese & 154 & 10 & 0.84 & $(0.47,1.52)$ & \\
\hline
\end{tabular}


Table 1. Cont.

\begin{tabular}{|c|c|c|c|c|c|}
\hline & $\mathbf{n}$ & $\begin{array}{l}\text { Use public } \\
\text { transport to } \\
\text { commute to } \\
\text { work }(\%)\end{array}$ & OR* & $95 \%$ CI & p-value \\
\hline Physical activity levels & & & & & 0.55 \\
\hline Insufficiently active & 391 & 13 & 1.00 & Referent & \\
\hline Sufficiently active & 796 & 12 & 0.90 & $(0.62,1.29)$ & \\
\hline Minutes spent walking / week & & & & & 0.02 \\
\hline $0-30$ & 323 & 11 & 1.00 & Referent & \\
\hline $31-100$ & 273 & 10 & 0.85 & $(0.50,1.46)$ & \\
\hline $101-210$ & 306 & 17 & 1.75 & $(1.10,2.78)$ & \\
\hline$>210$ & 286 & 10 & 1.03 & $(0.62,1.69)$ & \\
\hline
\end{tabular}

* Adjusted for age group, sex, and sampling weights.

Data presented in Table 2 shows the relationship between the likelihood of engaging in public transport when compared to urban design and travel measures. Significant associations existed for all urban design and travel variables in the univariate analysis after adjustment for age, sex, and sample weights when contrasted with the likelihood of taking public transport to the worksite. When compared to the respective reference categories, those who reported no access to car parking at the worksite, lived less than 200 meters away from a bus stop, worked in the Auckland CBD, had limited automobile access, traveled 11-15 kilometers to work, perceived public transport as accessible, or did not have a valid license, company car, or require a vehicle for work purposes, were more likely to use public transport for commuting to the worksite.

All statistically significant measures in the univariate models were considered for inclusion in the multivariate model. Marital status and number of minutes walking per week were the only variables that were not selected for the multivariate model; with the exception of travel distance, all the urban design and travel measures remained significant in the multivariate model. There were moderate adjustments of the odds ratios from the univariate models to the multivariate model but no changes in statistical significance. This demonstrates the importance of these factors to travel mode choice between public and private motorized transport. The fact that travel distance was not picked up by the multivariate model demonstrates that measures of accessibility to public transport, automobiles, and parking appear to override the effect of distance for this sample. 
Table 2. Likelihood of commuting to work by public transport compared with urban design and travel measures.

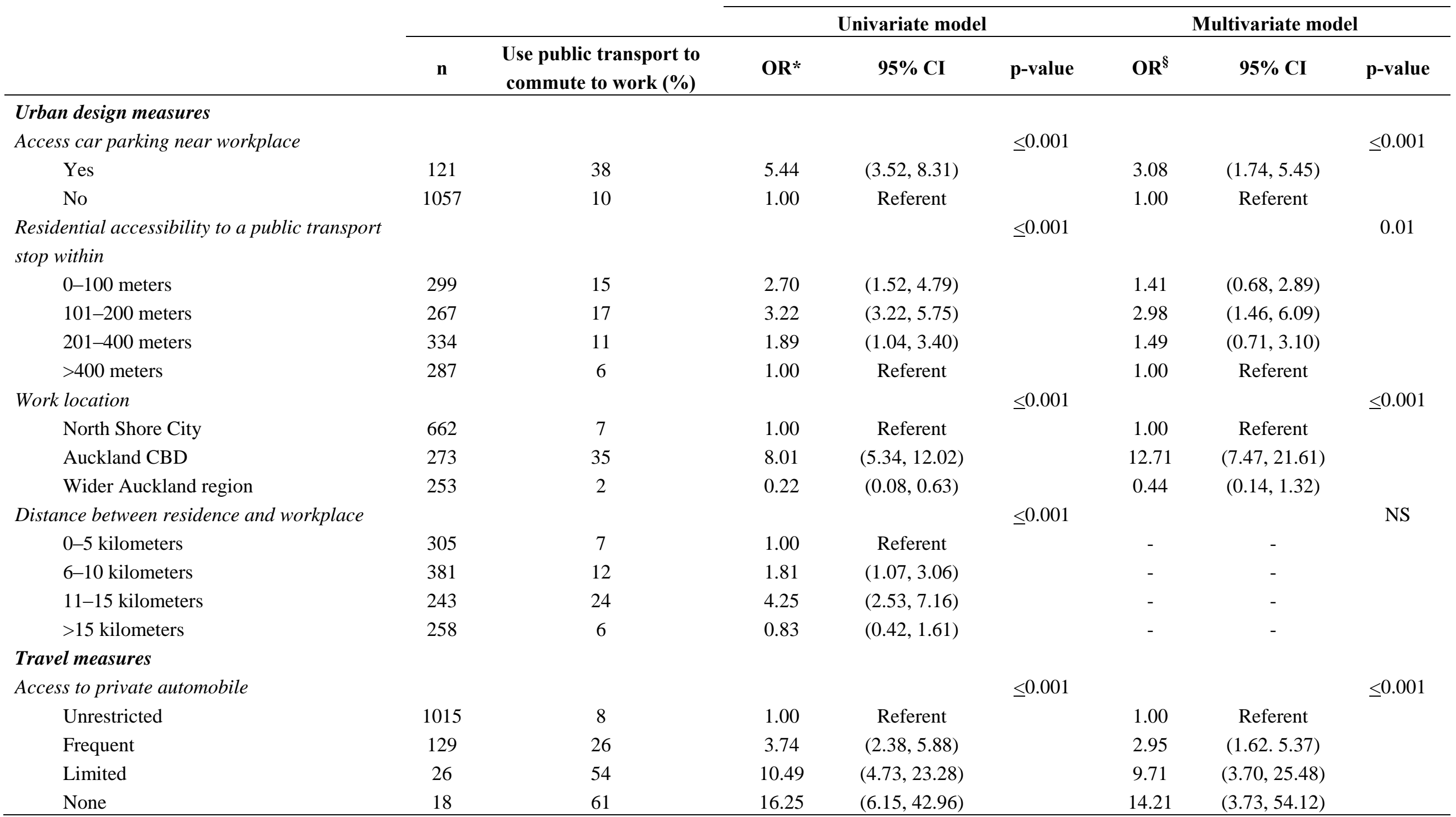


Table 2. Cont.

\begin{tabular}{|c|c|c|c|c|c|c|c|c|}
\hline & \multirow[b]{3}{*}{$\mathbf{n}$} & \multirow[b]{3}{*}{$\begin{array}{l}\text { Use public transport to } \\
\text { commute to work (\%) }\end{array}$} & \multirow{2}{*}{\multicolumn{3}{|c|}{ Univariate model }} & \multirow{2}{*}{\multicolumn{3}{|c|}{ Multivariate model }} \\
\hline & & & & & & & & \\
\hline & & & OR* & 95\% CI & p-value & $\mathbf{O R}^{\S}$ & $95 \% \mathrm{CI}$ & p-value \\
\hline \multicolumn{9}{|l|}{ Travel measures } \\
\hline \multicolumn{9}{|l|}{ Hold current driver's license } \\
\hline No & 32 & 56 & 8.41 & $(4.06,17.40)$ & & 4.74 & $(1.71,13.16)$ & \\
\hline Yes & 1156 & 11 & 1.00 & Referent & & 1.00 & Referent & \\
\hline Require automobile for work & & & & & $\leq 0.001$ & & & 0.002 \\
\hline No requirements & 615 & 19 & 17.20 & $(5.42,54.63)$ & & 7.67 & $(2.29,25.64)$ & \\
\hline Car required for work & 363 & 7 & 5.67 & $(1.71,18.82)$ & & 3.64 & $(1.03,12.87)$ & \\
\hline Access to a company car & 210 & 1 & 1.00 & Referent & & 1.00 & Referent & \\
\hline Perceive public transport as accessible & & & & & $\leq 0.001$ & & & $\leq 0.001$ \\
\hline Disagree & 232 & 7 & 1.00 & Referent & & 1.00 & Referent & \\
\hline Neutral & 122 & 5 & 0.60 & $(0.23,1.54)$ & & 0.38 & $(0.11,1.37)$ & \\
\hline Agree & 796 & 15 & 2.31 & $(1.38,3.87)$ & & 2.59 & $(1.34,5.03)$ & \\
\hline Don't know & 38 & 3 & 0.31 & $(0.04,2.42)$ & & 0.66 & $(0.08,5.74)$ & \\
\hline
\end{tabular}

\footnotetext{
* Adjusted for age group, sex, and sampling weights; ${ }^{\S}$ Adjusted for age group, sex, sampling weights, and all other variables in the model.
} 


\section{Discussion}

Consistent with existing research [8,19], these findings showed that prevalence levels for commuting to work via public transport within this sample were low. Despite the high reliance on motorized transport for traveling to an occupation, relationships existed between urban design and travel variables with public transport. Respondents who had an objectively-measured public transport stop proximal to their residence $(<200$ meters) or perceived public transport as being accessible were more likely to commute to work via mass transit. Conversely, those who perceived they have accessibility to car parking at their worksite or had a company car available were more likely to commute to work by private vehicle. These findings indicated that work-related travel behaviors are strongly associated with issues of convenience and accessibility. Interestingly, significant differences also existed by worksite location, and this has been suggested to be a function of traffic density, public transport convenience, and cost of car parking [30,31]. Acceptable employment locations may be further limited for those with no car and limited public transport accessibility. Although accessibility to free car parking was not assessed in the survey, the Auckland CBD has limited car parking availability, of which the majority is metered or restricted, whereas the other two settings have reduced traffic densities and greater opportunities to access car parking free of charge.

Expected relationships were shown between travel measures and public transport engagement. Respondents who reported greater car accessibility or relied on a vehicle for work purposes were more likely to commute to the worksite via private automobile. Previous New Zealand research has shown that those who reported limited car availability were approximately six times more likely to walk or cycle to the worksite when compared with adults with unlimited vehicle access [32]. In addition, nearly half of the sample identified that they required an automobile for work purposes. These relationships were not surprising as a vehicle is purchased for or provided by an employer in the first instance for transportation to frequently traveled destinations, such as a worksite.

Similar to previous research $[13,15,16]$, we detected relationships between public transport engagement and walking levels; however, this appears to be a complex relationship in the present study with significantly increased public transport engagement in participants achieving 101-210 minutes of walking per week but a reduction in those achieving more than 210 minutes of walking per week. One potential reason for these relationships are that there may be a maximum amount of time that respondents would consider time efficient for walking as part of a trip-chain in their work-related travel. In addition, no significant relationships were shown between overall physical activity and BMI with public transport, however there was a non-significant trend indicating that those who engaged in public transport were less likely to be obese. Possible reasons for our lack of associations between commute modes with these health variables is because of the small numbers of respondents who engaged in public transport and the lack of sensitivity from the self-report measurement tools used to assess overall physical activity engagement and BMI. Furthermore, no causality could be inferred because of the cross-sectional research design. Future research should seek to investigate health and public transport relationships with objective measures and examine larger samples of people with diverse travel behaviors.

As demonstrated by our findings and earlier work [33], travel behaviors have been linked to life stage and lifestyle, and although neighborhood preference was not assessed in this study, the 
importance of locational self-selection should not be underestimated as people may have chosen to live in a specific environment that supported their preferred travel behaviors (e.g., may deliberately live proximally to a public transport stop so they will not have to travel to their worksite by car; alternatively they may choose to work in environments where car parking is readily available). Previous research has supported the link between neighborhood self-selection and travel behaviors [33-35]. For example, Frank et al., [34] demonstrated evidence of an increased desire to walk for transport being associated with living in a more walkable environment, with a substantial proportion of people (16\%) being mismatched between their actual and preferred neighborhood based on walkability. Respondents who preferred a less walkable neighborhood reported only modest amounts of walking irrespective of where they lived.

Although this research adds further weight to case that the land use and transport infrastructure planning influences travel behaviors, limitations are evident. Apart from assessing public transport stops and distance to work objectively (through GIS), all other measures were self-reported. A large portion of respondents also reported requiring an automobile for work purposes throughout the day; yet the purpose of automobile use was not examined. It may be that people require motorized transport for trip chaining purposes, such as transporting children, as well as mobility throughout the day. Public transport connectivity and frequency were also not assessed, and it is likely that these would have influenced travel mode choice beyond having a public transport stop proximal to the residential address. We recognize that while some central factors related to travel behavior were examined in this paper, more detailed measures such as occupation type, number of children in the household, childcare facilities, and attitudes toward travel were beyond the scope of the survey administered. Future research needs to understand daily travel patterns more comprehensively in order to develop effective interventions to reduce private automobile travel. Other limitations of this study include the cross-sectional design that did not allow measurement of causal linkages and the low survey response rate may have influenced the representativeness of the findings.

\section{Conclusions}

Translating these findings to land use planning strategies and transport infrastructure provision will provide much utility for promoting sustainable transport behaviors. Work-related commuting appears to be a product in-part of convenience and accessibility constraints; when a public transport stop is proximal people are more likely to travel via that mode, whereas having car parking available at the worksite is positively associated with work-related car travel. As such, at the population-level public transport has to be perceived as accessible and likely be within a 200-meter radius of a residence for it to be used as a work-related transport mode. Alternatively, restricting car parking around worksites will likely hold utility for reducing the reliance on private motorized transport. Providing these environments is the first step to enacting change, but long-term substantial changes will arise from providing viable travel alternatives, promoting those alternatives, minimizing preferred transport mode costs, and developing specific strategies to target at-risk life stage population groups. 


\section{Acknowledgements}

Sport and Recreation New Zealand (SPARC) provided funding for the Active Friendly Environments project. HMB is supported by a New Zealand National Heart Foundation Research Fellowship (Grant No. 1280).

\section{References}

1. Cao, X.; Handy, S.L.; Mokhtarian, P. The influences of the built environment and residential self-selection on pedestrian behavior: evidence from Austin, TX. Transportation 2006, 33, 1-20.

2. Handy, S.L.; Cao, X.; Mokhtarian, P. Self-selection in the relationship between the built environment and walking. J. Am. Plann. Assn. 2006, 72, 55-74.

3. Librett, J.; Yore, M.M.; Schmid, T.L.; Kohl, H.W. Are self-reported physical activity levels associated with perceived desirability of activity-friendly communities? Health Place 2007, 13, 767-773.

4. Schwanen, T.; Mokhtarian, P. What affects commute mode choice: neighborhood physical structure or preferences toward neighborhoods? J. Trans.p Geog. 2005, 13, 83-99.

5. Cerin, E.; Leslie, E.; du Toit, L.; Owen, N.; Frank, L.D. Destinations that matter: Associations with walking for transport. Health Place 2007, 13, 713-724.

6. Lund, H. Testing the claims of New Urbanism. J. Am. Plann. Assn. 2003, 69, 414-429.

7. Saelens, B.; Sallis, J.F.; Black, J.B.; Chen, D. Neighborhood-based differences in physical activity: An environment scale evaluation. Am. J. Public Health 2003, 93, 1552-1558.

8. NHTS: Highlights of the 2001 National Household Travel Survey; US Department Transport Bureau and Transportation Statistics: Washington, DC, USA, 2003.

9. Haines, A.; McMichael, A.J.; Smith, K.R.; Roberts, I.; Woodcock, J.; Markandya, A.; Armstrong, B.G.; Campbell-Lendrum, D.; Dangour, A.D.; Davies, M.; et al. Public health benefits and strategies to reduce greenhouse-gas emissions: Overview and implications for policy makers. Lancet 2009, 374, 2104-2114.

10. Frank, L.D. Community design and individual well being: The multiple impacts of the built environment on public health. In Proceedings of the Obesity and Built Environment Conference of the National Institute of Environmental Health Services, Washington, DC, USA, 24-26 May 2004.

11. Oskamp, S. A sustainable future for humanity? Am. Psychol. 2000, 55, 496-508.

12. Frank, L.D.; Sallis, J.F.; Conway, T.L.; Chapman, J.E.; Saelens, B.E.; Bachman, W. Many pathways from land use to health: Associations between neighborhood walkability and active transportation, body mass index, and air quality. J. Am. Plann. Assn. 2006, 72, 75-87.

13. Villanueva, K.; Giles-Corti, B.; McCormack, G. Achieving 10,000 steps: A comparison of public transport users and drivers in a University setting. Prev. Med. 2008, 47, 338-341.

14. Badland, H.M.; Schofield, G.M. Health associations with transport-related physical activity and motorized travel to destinations. Int. J. Sustain. Transp. 2008, 2, 77-90.

15. Besser, L.; Dannenberg, A. Walking to public transit: steps to help meet physical activity recommendations. Am. J. Prev. Med. 2005, 29, 273-280. 
16. Wener, R.; Evans, G. A morning stroll: Levels of physical activity in car and mass transit commuting. Environ. Behav. 2007, 39, 62-74.

17. Handy, S.L.; Boarnet, M.G.; Ewing, R.; Killingsworth, R. How the built environment affects physical activity: Views from urban planning. Am. J. Prev. Med. 2002, 23, 64-73.

18. New Zealand Travel Survey Report 2005/06; Land Transport New Zealand: Wellington, New Zealand, 2007.

19. Giuliano, G.; Dargay, J. Car ownership, travel, and land use: A comparison of the US and Great Britain. Transp. Res. Pt. A: Policy Pract. 2006, 40, 106-124.

20. Badland, H.M.; Schofield, G.M.; Garrett, N. Travel behavior and objectively measured urban design variables: Associations for adults traveling to work. Health Place 2008, 14, 85-95.

21. Census 2006; Statistics New Zealand: Wellington, New Zealand, 2007.

22. Sullivan, C.; Oakden, J.; Young, J.; Butcher, H.; Lawson, R. Obstacles to Action: A Study of New Zealanders' Physical Activity and Nutrition; Sport and Recreation New Zealand: Wellington, New Zealand, 2003.

23. Badland, H.M.; Schofield, G.M. Test-retest reliability of a survey to measure transport-related physical activity in adults. Res. Q. Exerc. Sport 2006, 77, 386-390.

24. Mackay, L.; Schofield, G.M.; Schluter, P.J. Validation of self report measures of physical activity: A case study using the New Zealand physical activity questionnaire (NZPAQ). Res. Q. Exerc. Sport 2007, 78, 189-196.

25. Armstrong, T.; Bauman, A.E.; Davies, J. Physical Activity Patterns of Australian Adults. Results of the 1999 National Physical Activity Survey; Australian Institute of Health and Welfare: Canberra, Australia, 2000.

26. At Least Five a Week: Evidence on the Impact of Physical Activity and Its Relationship to Health. A Report from the Chief Medical Officer; Department of Health: London, UK, 2004.

27. The Asia-Pacific Perspective: Redefining Obesity and Its Treatment; World Health Organization: Geneva, Switzerland, 2000.

28. Mummery, W.K.; Duncan, M.J.; Kift, R. Socio-economic differences in public opinion regarding fluoridation in Queensland. Aust. NZ J. Pub. Health 2007, 31, 336-339.

29. Ainsworth, B.E.; Wilcox, S.; Thompson, W.W.; Richter, D.L.; Henderson, K.A. Personal, social, and physical environmental correlates of physical activity in African-American women in South Carolina. Am. J. Prev. Med. 2003, 25, S23-S29.

30. Ewing, R.; Cervero, R. Travel and the built environment: A synthesis. Transp. Res. Rec. 2001, 1780, 87-114.

31. Willson, R.; Shoup, D. Parking subsidies and travel choices: Assessing the evidence. Transportation 1990, 17, 141-157.

32. Badland, H.M.; Schofield, G.M. Understanding the relationships between overall physical activity, transport-related physical activity, and personal car accessibility in adults. Transportation 2008, 35, 363-374.

33. Scheiner, J.; Holz-Rau, C. Travel mode choice: Affected by objective or subjective determinants. Transportation 2007, 34, 487-511. 
34. Frank, L.D.; Saelens, B.E.; Powell, K.E.; Chapman, J.E. Stepping towards causation: Do built environments or neighborhood and travel preferences explain physical activity, driving, and obesity? Soc. Sci Med. 2007, 65, 1898-1914.

35. Handy, S.L.; Cao, X.; Mokhtarian, P. Active Travel: The Role in Self-Selection in Explaining the Effect of Built Environment on Active Travel; Robert Wood Johnson Foundation San Diego State University: San Diego, CA, USA, 2009.

(C) 2010 by the authors; licensee Molecular Diversity Preservation International, Basel, Switzerland. This article is an open-access article distributed under the terms and conditions of the Creative Commons Attribution license (http://creativecommons.org/licenses/by/3.0/). 